\title{
The dumping syndrome and the hydrogen ion concentration of the gastric contents
}

\author{
JAMES P. S. THOMSON, R. C. G. RUSSELL, M. HOBSLEY, AND L. P. LE QUESNE \\ From the Department of Surgical Studies, The Middlesex Hospital Medical School, London
}

SUMMARY Forty patients after vagotomy (truncal vagotomy 18, selective vagotomy 22) with a drainage procedure were given $200 \mathrm{ml}$ of $50 \%$ dextrose by mouth (dumping provocation test), the symptoms induced being noted, and any fall in plasma volume was assessed by serial measurement of the haematocrit. An insulin gastric secretion test was also performed on each patient.

Twenty of the patients had dumping symptoms of varying severity after ordinary meals: in all 20 patients these symptoms were reproduced by the dumping provocation test, which also produced similar symptoms in a further three patients.

The hydrogen ion concentration of the gastric contents was significantly lower in the basal state and after insulin hypoglycaemia in those patients with dumping symptoms than in those without such symptoms. Furthermore there was a significant inverse correlation between the hydrogen ion concentration of the gastric contents in the basal and stimulated state and the rate of plasma volume fall.

The results show that the occurrence of the dumping syndrome after vagotomy with a drainage procedure is related to the hydrogen ion concentration of the gastric contents. The possible significance of this finding is discussed.

The object of operations designed to treat chronic duodenal ulcer is to reduce the hydrogen ion concentration of the gastric contents. It is surprising, therefore, that a possible relationship between the extent to which this object has been achieved, and the dumping syndrome that may be a sequel of these operations, has not been thoroughly examined. The present study investigates this relationship in patients after vagotomy with a drainage procedure.

\section{Patients Studied}

Studies were carried out on 40 patients who had had a vagotomy (truncal vagotomy 18 , selective vagotomy 22) with a drainage procedure HeinekeMikulicz pyloroplasty 18, gastroduodenostomy 12 , gastrojejunostomy 10) as treatment of a chronic duodenal ulcer. The age of the patients ranged from 22 to 77 (average $=44$ years); six were women and 34 were men. Two of the patients studied were undergoing investigation for symptoms of recurrent peptic ulceration and five for severe postcibal

Received for publication 15 January 1974. symptoms. The remaining 33 patients were volunteers: 27 were studied in the immediate postoperative period and the remaining six at varying times later after operation. Of those studied shortly after operation, 15 were also studied before operation.

\section{Methods}

Each patient received a dumping provocation test and an insulin gastric secretion test. Both tests were performed within 10 days of each other.

\section{DUMPING PROVOCATION TEST}

The patients were studied in a semirecumbent position after an eight-hour fast. They were given an oral hypertonic glucose meal $(200 \mathrm{ml}$ of a $50 \%$ solution). Symptoms occurring during the test were noted. Two fasting blood samples were obtained, without stasis, from an indwelling cannula in a large antecubital vein for estimation of haematocrit (packed cell volume). Subsequent samples were taken at five, 10, 15, $20,25,30,40,60,90$, and 120 minutes after the glucose load. The haematocrit was determined using 
the Hawksley microhaematocrit technique (Sanders, 1961). The percentage fall in plasma volume $(x)$ at each sampling time was calculated from the formula

$$
x=100-\left[\frac{\mathrm{Ht}_{1}}{100-\mathrm{Ht}_{1}} \times \frac{100-\mathrm{Ht}_{2}}{\mathrm{Ht}_{2}}\right] \times 100
$$

Where $\mathrm{Ht}_{1}$ was the average of the two fasting haematocrit determinations and $\mathrm{Ht}_{2}$ the haematocrit at each of the subsequent times of sampling (Le Quesne, Hobsley, and Hand, 1960). For each individual the result was expressed as the rate of percentage fall in plasma volume ( $\%$ per minute) calculated from the straight line which best fitted (the method of least squares) all the values of the percentage plasma volume fall from zero to the nadir (fig 1).

INSULIN GASTRIC SECRETION TEST

The patients were studied after an eight-hour fast. A nasogastric tube was positioned in the stomach

\section{Time-minutes}

\begin{tabular}{rrrrrrr}
0 & 10 & 2030 & 40 & 60 & 90 & 120 \\
\hline & 1 & 1 & 1 & 1 & 1 & 1
\end{tabular}

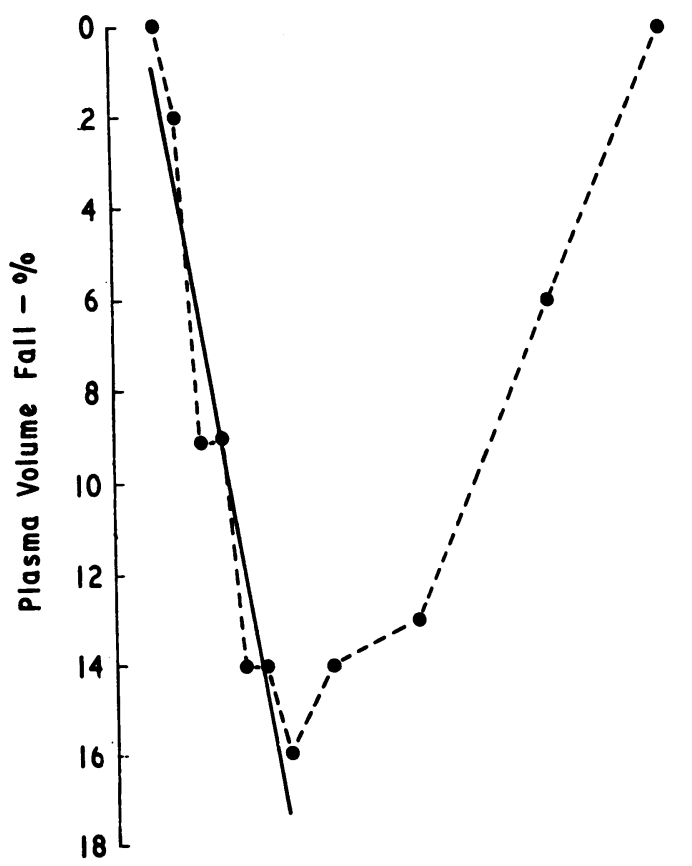

Fig 1 A typical curve of the percentage fall in plasma volume plotted against time in a patient with dumping symptoms after oral hypertonic glucose. The calculated straight line is indicated (see text). The rate of percentage fall of plasma volume is $0.55 \%$ per minute. using the technique of Hassan and Hobsley (1970). Gastric juice was collected by continuous suction in periods of 10 minutes for a basal 30 minutes after initial emptying of the stomach, and for two hours after a single intravenous injection of soluble insulin $(0.2$ units per kilogram). Venous blood samples were taken for estimation of blood sugar (alkaline-ferricyanide method, Hoffman 1937, using the AutoAnalyzer) to ensure that there had been an adequate hypoglycaemic stimulus.

The variables examined were (1) the basal hydrogen ion concentration (m-equiv per litre), the average of the three samples collected; (2) the peak hydrogen ion concentration (m-equiv per litre), the average of the highest 10-minute hydrogen ion concentration and that of the previous and subsequent 10-minute periods; (3) the volume of gastric juice $(\mathrm{ml})$ collected for the basal and peak periods as in (1) and (2) above; (4) the 30-minute hydrogen ion output (m-equiv) for the basal and peak periods as in (1) and (2) above.

No corrections were applied to these data for pyloric loss of gastric juice or duodenogastric reflux (see Discussion).

Non-parametric statistical tests were used to analyse the data: Wilcoxon's test for group analyses and Spearman's test for rank correlations.

\section{Results}

OCCURRENCE OF DUMPING SYMPTOMS

None of the 15 patients studied before operation had dumping symptoms clinically or when challenged with the hypertonic glucose meal.

Twenty of the patients studied after operation had dumping symptoms of varying severity after ordinary meals and these symptoms were reproduced during the dumping provocation test. An additional three patients had dumping symptoms during the test who did not have such symptoms after ordinary meals. For the purpose of the following analysis the presence or absence of symptoms during the dumping provocation test was used to divide the patients studied postoperatively into two groups: 17 patients who were symptom-free and 23 patients who had dumping symptoms. There were no significant differences in the occurrence of dumping symptoms between those patients who had truncal vagotomy and selective vagotomy, between the patients with the three different types of drainage procedure, and between those patients who were studied in the immediate postoperative period and those studied after six months (table I).

THE RATE OF PERCENTAGE FALL OF PLASMA VOLUME

The rate of percentage fall of plasma volume in the 


\begin{tabular}{|c|c|c|c|c|c|c|c|}
\hline & \multicolumn{2}{|c|}{ Type of Vagotomy } & \multicolumn{3}{|c|}{ Type of Drainage Procedure } & \multicolumn{2}{|c|}{ Time of Studies } \\
\hline & Truncal & Selective & $P(H M)$ & $G D$ & $\boldsymbol{G J}$ & Immediate & After Six Months \\
\hline
\end{tabular}

Table I Occurrence of dumping symptoms following oral hypertonic glucose in patients with the differing operative procedures and at different times of study

${ }^{1}$ Using the $\chi^{2}$ test there were no significant differences between any of these groups. P(HM) = Heineke-Mikulicz pyloroplasty;

GD = gastroduodenostomy; GJ = gastrojejunostomy.

various groups of patients is shown in figure 2. Those patients with dumping symptoms had a significantly greater rate of percentage fall in plasma volume (mean $=0.46 \%$ per minute, $\mathrm{SEM} \pm 0.03$ )



Fig 2 The results of the dumping provocation test for the three groups studied. The mean and standard error of the mean are indicated for each group. than those postoperative patients without such symptoms (mean $=0.15 \%$ per minute, SEM \pm 0.04 ) $(P<0.01)$. However, there was no significant difference between the symptom-free postoperative and the preoperative patients (mean $=0.08 \%$ per minute, SEM \pm 0.02 ).

There was no significant difference in the rate of plasma volume fall between the different operative procedures or between the different times of study (table II).

\section{THE BASAL HYDROGEN ION}

\section{CONCENTRATION}

The means of the basal hydrogen ion concentration in the preoperative and two postoperative groups are shown in table III. The basal hydrogen ion concentration in those patients with dumping symptoms was significantly lower than in those postoperative patients without such symptoms $(P<0.01)$. There was no significant difference between the symptomfree postoperative and preoperative patients. Taking all the postoperative patients together there was a significant inverse correlation between the basal hydrogen ion concentration and the rate of percentage fall of plasma volume (Spearman's correlation coefficient, $\left.\mathrm{r}_{\mathrm{s}}=-0.66, \mathrm{P}<0.001\right)$.

\section{THE PEAK HYDROGEN ION CONCENTRATION} AFTER INSULIN HYPOGLYCAEMIA

The means of the peak hydrogen ion concentration after insulin hypoglycaemia in the three groups are shown in table III. Those patients with dumping symptoms had a siginificantly lower peak hydrogen ion concentration than those without such symptoms $(P<0.01)$. In addition, the symptom-free postoperative patients had significantly lower peak values than the preoperative patients $(P<0.01)$. Furthermore, when all the postoperative patients were taken together there was a highly significant inverse correlation between the peak hydrogen ion concentration and the rate of percentage fall of plasma volume $\left(r_{s}=-0.78, P<0.001\right)$ (fig 3). 


\begin{tabular}{|c|c|c|c|c|c|c|c|}
\hline & \multicolumn{2}{|c|}{ Type of Vagotomy } & \multicolumn{3}{|c|}{ Type of Drainage Procedure } & \multicolumn{2}{|c|}{ Time for Studies } \\
\hline & Truncal & Selective & $P(H M)$ & $G D$ & GJ & Immediate & After Six Months \\
\hline $\begin{array}{l}\text { Rate of plasma volume fall } \\
\text { (\% per minute) } \\
\text { Basal }\left[\mathrm{H}^{+}\right](\text {m-equiv } / \mathbf{l}) \\
\text { Peak }\left[\mathrm{H}^{+}\right](\text {m-equiv } / \mathbf{l})\end{array}$ & $\begin{array}{l}0.30( \pm 0.04) \\
25 \cdot 2( \pm 4 \cdot 8) \\
48 \cdot 4( \pm 7 \cdot 8)\end{array}$ & $\begin{array}{l}0.35( \pm 0.05) \\
25 \cdot 3( \pm 6.1) \\
37.1( \pm 7.9)\end{array}$ & $\begin{array}{l}0.26( \pm 0.04) \\
30 \cdot 7( \pm 5 \cdot 7) \\
50 \cdot 3( \pm 8 \cdot 5)^{1}\end{array}$ & $\begin{array}{l}0.39( \pm 0.09) \\
16 \cdot 8( \pm 6 \cdot 6) \\
44 \cdot 0( \pm 11 \cdot 7)\end{array}$ & $\begin{array}{l}0.36( \pm 0.05) \\
25 \cdot 7( \pm 8 \cdot 7) \\
25 \cdot 3( \pm 7 \cdot 1)^{1}\end{array}$ & $\begin{array}{l}0 \cdot 29( \pm 0 \cdot 0 \\
28 \cdot 2( \pm 4 \cdot 8) \\
43 \cdot 1( \pm 6 \cdot 7)\end{array}$ & $\begin{array}{l}0.41( \pm 0.07) \\
19 \cdot 1( \pm 6.0) \\
40 \cdot 2( \pm 10.5)\end{array}$ \\
\hline
\end{tabular}

Table II Means of the rate of plasma volume fall and of the basal and peak hydrogen ion concentrations after the different operative procedures and at the different times of study ${ }^{1}$

${ }^{1}$ The only pair which is significantly different $(P<0.05)$ is marked *. The standard error of the mean is shown in brackets. $\mathbf{P}(\mathrm{HM})=$ Heineke-Mikulicz pyloroplasty; $\mathbf{G D}=$ gastroduodenostomy; $\mathbf{G J}=$ gastrojejunostomy

\begin{tabular}{lrll}
\hline & Preoperative & Postoperative \\
\cline { 3 - 3 } & & Symptom Free & Dumping Symptoms \\
\hline $\begin{array}{l}\text { Basal }\left[\mathrm{H}^{+}\right] \\
\text {(m-equiv/1) }\end{array}$ & $39 \cdot 1 .( \pm 6 \cdot 3)$ & $36 \cdot 5( \pm 6 \cdot 1)$ & $16 \cdot 9( \pm 4 \cdot 5)$ \\
$\begin{array}{l}\text { Peak }\left[\mathrm{H}^{+}\right] \\
\text {(m-equiv/1) }\end{array}$ & $104 \cdot 6( \pm 6 \cdot 5)$ & $68 \cdot 9( \pm 7 \cdot 6)$ & $22 \cdot 4( \pm 4 \cdot 8)$ \\
\hline
\end{tabular}

Table III Mean hydrogen ion concentration of the gastric contents in the basal state and the peak value after insulin hypoglycaemia for the three groups studied ${ }^{1}$

${ }^{1}$ The standard error of the mean is shown in brackets.



Fig 3 The correlation between the peak $\left[\mathrm{H}^{+}\right]$after insulin hypoglycaemia and rate of percentage fall of plasma volume $\left(r_{\mathrm{s}}=0.78, \mathrm{P}<0.001\right) . \mathrm{O}=$ symptom free, $\bigcirc=$ dumping symptoms after oral hypertonic glucose.

\section{THE DIFFERENCE BETWEEN THE BASAL AND} PEAK HYDROGEN ION CONCENTRATIONS In the 17 symptom-free postoperative patients there was a significant rise $(P<0.01)$ from the basal to the peak hydrogen ion concentration. The mean rise was 32.4 m-equiv per litre (SEM \pm 5.5$)$. However, in the 23 patients with dumping symptoms, the mean rise of 5.5 m-equiv/1 (SEM \pm 2.9$)$ from the basal to the peak hydrogen ion concentration was not significant (fig 4).

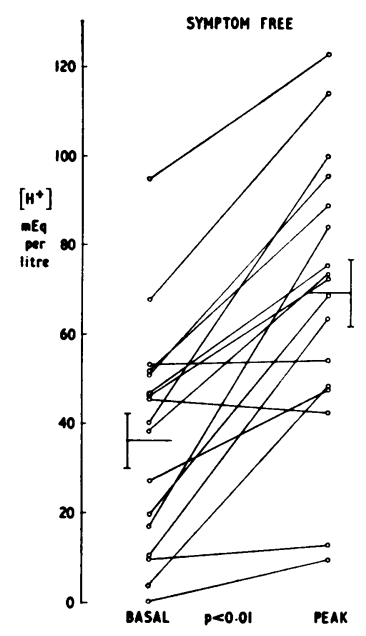

DUMPING SYMPTOMS

Fig 4 The differences between basal $\left[\mathrm{H}^{+}\right]$and peak $\left[\mathrm{H}^{+}\right]$after insulin hypoglycaemia for each individual in the two postoperative groups studied. The mean and standard error of the mean for each group are indicated.

\section{ANALYSIS OF RESULTS USING THE CRITERIA OF HOLLANDER (1948)}

Table IV shows the correlation between the results of the dumping provocation test and the insulin gastric secretion test analysed using Hollander's criteria. There was a significantly greater proportion of patients with dumping symptoms in those who had a Hollander-negative test $\left(\chi^{2}=13.849, \mathrm{P}<0.0005\right)$.

\begin{tabular}{lcc}
\hline Hollander's Criteria & Symptom Free & Dumping Symptoms \\
\hline Negative & 4 & 20 \\
Positive & 13 & 3
\end{tabular}

Table IV Results of the 40 postoperative patients studied analysed using Hollander's criteria

$x^{2}=13 \cdot 849, P<0.0005$. 


\begin{tabular}{lccc}
\hline & Preoperative & Postoperative & \\
\cline { 2 - 3 } & & Symptom Free & Dumping Symptoms \\
\hline Basal volume $(\mathrm{ml})$ & $49 \cdot 1( \pm 7 \cdot 3)$ & $43 \cdot 2( \pm 7 \cdot 1)$ & $42 \cdot 1( \pm 5 \cdot 5)$ \\
Peak volume $(\mathrm{ml})$ & $119 \cdot 9( \pm 14 \cdot 8)$ & $68 \cdot 1( \pm 10 \cdot 0)$ & $37 \cdot 6( \pm 3 \cdot 4)$ \\
\hline
\end{tabular}

Table $\mathrm{V}$ Mean volumes of gastric juice collected in the basal and peak 30-minute periods ${ }^{1}$

${ }^{1}$ The standard error of the mean is shown in brackets.

\begin{tabular}{lclc}
\hline & Preoperative & Postoperative & Dumping Symptoms \\
\hline $\begin{array}{l}\text { Basal 30-minute hydrogen ion output } \\
\text { (m-equiv) }\end{array}$ & $2 \cdot 1( \pm 0.6)$ & Symptom Free & $0.6( \pm 0.2)$ \\
$\begin{array}{l}\text { Peak 30-minute hydrogen ion output } \\
\text { (m-equiv) }\end{array}$ & $13 \cdot 5( \pm 1 \cdot 9)$ & $1.6( \pm 0 \cdot 3)$ & $0.9( \pm 0.2)$ \\
\hline
\end{tabular}

Table VI Mean hydrogen ion output in the basal state and the peak value after insulin hypoglycaemia for the three groups studied ${ }^{1}$

${ }^{2}$ The standard error of the mean is shown in brackets.

THE EFFECT OF THE DIFFERENT OPERATIVE PROCEDURES AND THE DIFFERENT TIMES OF STUDY ON THE HYDROGEN ION CONCENTRATION

There were no significant differences in the basal and the peak hydrogen ion concentrations between those patients who had a truncal or a selective vagotomy. In addition there were no significant differences in these volumes between the groups of patients who had the different drainage procedures with the exception of the difference in the peak hydrogen ion concentration between those with a pyloroplasty and those with a gastrojejunostomy $(\mathrm{P}<0.05)$.

There were no significant differences between the hydrogen ion concentrations of those studied immediately after operation and those studied after six months. These results are summarized in table II.

THE VOLUME OF GASTRIC JUICE

The means of the volumes of gastric juice collected in the basal and peak 30-minute periods are shown in table V. There was no significant difference in the volumes of the basal 30-minute period between the preoperative and two postoperative groups. However, the volumes of the peak 30-minute period in those patients with dumping symptoms were significantly less than in those without such symptoms $(P<0.01)$, and that in the symptom-free postoperative patients was significantly less than in the preoperative patients $(\mathrm{P}<0.01)$.

THE 30-MINUTE HYDROGEN ION OUTPUT

The results based on the 30-minute hydrogen ion output for the basal and peak periods in the preoperative and two postoperative groups are similar to those based on hydrogen ion concentration. They are shown in table VI. In the postoperative patients, in the basal period the 30-minute hydrogen ion output was significantly lower in those with dumping symptoms than in those without such symptoms $(\mathrm{P}<0.01)$; in the peak period the hydrogen ion output was significantly lower in those with dumping symptoms compared with those who were symptomfree $(P<0.01)$, and in the symptom-free postoperative patients compared with those studied preoperatively $(\mathrm{P}<0.01)$.

Furthermore, there was a significant inverse correlation between the plasma volume fall and the basal and the peak 30-minute hydrogen ion output $\left(r_{s}=-0.6727, P<0.001\right.$ and $r_{s}=-0.7665$, $P<0.001$, respectively).

\section{Discussion}

In the studies reported in this paper, dumping symptoms were provoked by the oral administration of hypertonic glucose. In a sense this is an artificial stimulus, but there is good evidence (Roberts, Randall, Farr, Kidwell, McNeer, and Pack (1954) and Le Quesne et al (1960) that the symptoms and changes produced in plasma volume by hypertonic glucose are the same as those after a normal meal. Furthermore, as borne out by this study, the number of patients who develop symptoms after oral hypertonic glucose is almost identical to the number who experience significant dumping symptoms after a meal.

The results of this investigation show that in patients after a vagotomy with a drainage proceedure, there is a correlation between the occurrence of dump- 
ing symptoms following oral hypertonic glucose and the hydrogen ion concentration of the gastric contents both in the basal state and after insulin hypoglycaemia. These results demonstrate that the lower the basal hydrogen ion concentration and the lower the peak hydrogen ion concentration after insulin hypoglycaemia, the greater is the liability to the dumping symptoms. In addition, in those patients with symptoms there is no significant difference between the basal and peak hydrogen ion concentrations, whereas in those patients without such symptoms the peak hydrogen ion concentration is significantly higher than the basal.

Similar observations were made when the values for the 30-minute hydrogen ion output were examined. The postoperative patients studied were not a homogeneous group: the patients had one of two types of vagotomy, one of three types of drainage procedure, and the times of study after operation varied considerably. However, despite this the overall conclusions reported here exhibit a high degree of statistical significance.

These findings, together with the analysis of the results in relation to Hollander's criteria, suggest that dumping symptoms are more liable to develop in patients in whom the operation has resulted in complete vagal denervation of the stomach. This may be the case. However, current work in this department suggests that the interpretation of postvagotomy insulin tests with respect to completeness of the nerve section demands the measurement of factors, such as pyloric loss and duodenal reflux, which affect the hydrogen ion concentration of the gastric juice, but which are not taken into account by the Hollander criteria. Therefore, it is not possible at the present time to make a definite statement concerning the relationship between occurrence of dumping symptoms and the completeness of vagus nerve section.

The only previous work relating the occurrence of the dumping syndrome to the results of an insulin gastric secretion test is that of Kennedy and Connell (1969). They claimed to have found a significantly greater proportion of 'dumpers' in those patients who had positive tests as judged by Hollander's criteria. This claim is contrary to the results described in this paper. However, on re-analysing their data, using the $\chi^{2}$ test, we were unable to confirm that their findings were statistically significant.

The reason for the association between the dumping syndrome and the ability of the stomach to secrete acid is not immediately apparent. However, a tentative explanation may be put forward. It is well established that the dumping syndrome is associated with a fall in plasma volume (Roberts et al, 1954; Le Quesne et al, 1960). This further study supports this fact. It has recently been established that the gastric emptying rate of hypertonic glucose is proportional to the fall of plasma volume it produces (Haynes, Thomson, Brown, and Keeling, 1973). Hunt (1957) has shown that in normal people and in patients suffering from chronic duodenal ulceration the rate of gastric emptying is inversely proportional to the hydrogen ion concentration of the gastric contents. It is therefore conceivable that after vagotomy with a drainage procedure the gastric hydrogen ion concentration influences the rate of gastric emptying in a similar way. Thus patients with a lower gastric hydrogen ion concentration would have a more rapid rate of gastric emptying and a greater liability to dumping symptoms and those with a higher gastric hydrogen ion concentration would have a slower rate of gastric emptying and a smaller liability to dumping symptoms.

It is worth recording that the volumes of gastric juice collected in the basal period were not significantly different in the two postoperative groups studied and that the difference in the means of the volumes collected in the peak 30-minute period between the symptom-free group and the group with dumping symptoms was only $30.5 \mathrm{ml}$. The addition of a volume of gastric juice of this order to the hypertonic glucose would not greatly reduce its osmotic pressure.

The occurrence of dumping symptoms following partial gastrectomy and even simple gastro-jejunostomy might also be explained on the basis of a lowering of the hydrogen ion concentration of the gastric contents-after partial gastrectomy by the removal of the greater part of the parietal cell mass and after gastrojejunostomy it is possible that reflux of alkaline intestinal contents may occur and so lower the hydrogen ion concentration.

In conclusion, the results of this study suggest that the occurrence of the dumping syndrome after vagotomy with a drainage procedure may be influenced by the hydrogen ion concentration of the gastric contents.

We wish to thank Dr A. L. Miller and the staff of the Courtauld Institute of Biochemistry for performing the blood sugar estimations, Mr J. V. Parkin and $\mathrm{Mr}$ R. G. Faber who performed some of the insulin gastric secretion tests, Mrs Sylvia Gambin and Mr Peter Whitfield for their technical help, and the Department of Medical Illustration for the diagrams.

\section{References}

Hassan, M. A., and Hobsley, M. (1970). Positioning of subject and of nasogastric tube during a gastric secretion study. Brit. med. J., 1, 458-460. 
Haynes, S., Thomson, J. P. S., Brown, N., and Keeling, D. H. (1973). A study of the relationship between the rate of gastric emptying and the dumping syndrome in patients after vagotomy and drainage. (Abst.) Brit. J. Surg., 60, 307-308.

Hoffman, W. S. (1937). A rapid photoelectric method for the determination of glucose in blood and urine. J. biol. Cl em., 120, 51-55.

Hollander, F. (1948). Laboratory procedures in the study of vagotomy? (with particular reference to the insulin test). Gastroenterology, $11,419-425$.

Hunt, J. N. (1957). Influence of hydrochloric acid on gastric secretion and emptying in patients with duodenal ulcer. Brit. med. J., 1, 681-684.

Kennedy, T., and Connell, A. M. (1969). Selective or truncal vagotomy
A double-blind, randomised controlled trial. Lancet, 1, 899-901.

Le Quesne, L. P., Hobsley, M., and Hand, B. H. (1960). The dumping syndrome. 1. Factors responsible for the symptoms. Brit. med. J., 1, 141-147.

Roberts, K. E., Randall, H. T., Farr, H. W., Kidwell, A. P., McNeer, G. P., and Pack, G. T. (1954). Cardiovascular and blood volume alterations resulting from intrajejunal administration of hypertonic solutions to gastrectomized patients; the relationship of these changes to the dumping syndrome. Ann. Surg., $140,631-640$.

Saunders, C. (1961). The packed red cell volume and the haemoglobin estimation using the Hawksley high-speed micro haematocrit centrifuge and the Hilger 'Spekker' photoelectric absorptiometer. Atomic Energy Research Establishment, Harwell, AERE-R 3729.

\section{The February 1974 Issue}

\section{THE FEBRUARY 1974 ISSUE CONTAINS THE FOLLOWING PAPERS}

Significance of intravascular coagulation and fibrinolysis in acute hepatic failure P. HILLENBRAND, S. P. PARBHOO, A. JEDRYCHOWSKI, AND SHEILA SHERLOCK

A controlled trial of heparin therapy in the coagulation defect of paracetamol-induced hepatic necrosis B. G. GAZZARD, R. CLARK, V. BORIRAKCHANYAVAT, AND ROGER WILLIAMS

Viral antibodies and autoantibodies in chronic liver disease D. R. TRIGER, J. B. KURTZ, AND RALPH WRIGHT

The portal pressure-blood volume relationship in cirrhosis DAVID S. ZIMMON AND RICHARD E. KESSLER

Immunoreactive gastrin components in human serum JENS F. REHFELD, FLEMMING STADIL, AND JøRGEN VIKELSøE

Extraction of circulating endogenous gastrin by the gastric fundus JOHN C. W. EVANS, DAVID D. REEDER, HORST D. BECKER, AND JAMES C. THOMPSON

Inhibitory effect of bromazepam on basal and betazole-stimulated gastric acid secretion in man G. STACHER AND DORIS STÄRKER

Unconjugated hyperbilirubinaemia in achalasia J. FEVERY, K. P. M. HEIRWEGH, AND J. De GROOTE
Defective biliary excretion of copper in Wilson's disease D. J. FROMMER

The sequential deposition of crystalline material in gallstones: Evidence for changing gallbladder bile composition during the growth of some stones $D$. JUNE SUTOR AND SUSAN E. WOOLEY

Trypsin and chymotrypsin in duodenal aspirate and faeces in response to secretin and cholecystokininpancreozymin J. K. SALE, D. M. GOLDBERG, B. THJODLEIFSSON, AND K. G. WORMSLEY

The effect of vagotomy and drainage on the small bowel flora G. G. BROWNING, K. A. BUCHAN, AND c. MACKAY

Properties of strains of Escherichia coli carried in different phases of ulcerative colitis E. MARY COOKE, SUSAN P. EWINS, J. HYWEL-JONES, AND J. E. LENNARD-JONES

Clinical evaluation of the ${ }^{14} \mathrm{C}$ fat absorption test P. J. BURRows, J. S. FLEMING, E. S. GARNETT, D. M. ACKERY, D. G. COLIN-JONES, AND J. BAMFORTH

Progress report Bile acid metabolism in infants and children G. M. MURPHY AND E. SIGNER

Notes and activities

Copies are still available and may be obtained from the PUBLISHING MANAGER, BRITISH MEDICAL ASSOCIATION, TAVISTOCK SQUARE, LONDON, WC1H 9JR, price $87 \frac{1}{2} \mathrm{p}$. 